\title{
Breakouts derived from image logs aid the estimation of maximum horizontal stress: A case study from Perth Basin, Western Australia
}

\author{
Mohammadali Faraji $^{1}$, Alireza Rezagholilou ${ }^{2}$, Mandana Ghanavati ${ }^{3}$, Ali Kadkhodaie ${ }^{4}$, David A. \\ Wood $^{5 \oplus *}$ \\ ${ }^{1}$ School of Environmental and Life Sciences, University of Newcastle, Callaghan, NSW 2308, Australia \\ ${ }^{2}$ WA School of Mines: Minerals, Energy and Chemical Engineering, Curtin University, Perth, WA 6102, Australia \\ ${ }^{3}$ Department of Petroleum Engineering, Amirkabir University of Technology (Tehran Polytechnic), Tehran, Iran \\ ${ }^{4}$ Earth Science Department, Faculty of Natural Science, University of Tabriz, Tabriz, Iran \\ ${ }^{5}$ DWA Energy Limited, Lincoln, LN5 9JP, UK
}

Keywords:

Circumferential borehole image logs

wellbore breakout

maximum horizontal stress

shear failure

stress polygon

Cited as:

Faraji, M., Rezagholilou, A., Ghanavati, M., Kadkhodaie, A., Wood, D. A. Breakouts derived from image logs aid the estimation of maximum horizontal stress: A case study from Perth Basin, Western Australia. Advances in

Geo-Energy Research, 2021, 5(1): 8-24, doi: 10.46690/ager.2021.01.03

\begin{abstract}
:
In-situ stresses are highly important for wellbore stability studies during drilling, completion and production. Different methods are available to estimate the horizontal stresses especially maximum horizontal stress. Typically, Circumferential Borehole Image Logs can be run to determine the direction and width of breakouts and then stresses at different depths based on the equation developed by Barton et al. (1988). This research focuses on image logs from Harvey-1 well located in the Southern Perth basin to compare the maximum horizontal stresses obtained by various methods. The magnitudes of stresses from the breakout width approach (Barton's method) exhibit a considerable offset in comparison with elastic methods. Further investigations show that the likely reason for the offset relates to the fundamental assumption of the breakout width approach in which shear failures are considered to be constrained to horizontal planes. Failures within the wellbore are not necessarily horizontal and can be developed in different non-planar trajectories with various angles to the horizontal plane. Furthermore, the possible in-situ stresses from regional studies are constrained by means of stress polygons against which the reliability of results from breakout methods can be checked. Results indicate that due diligence and special care must be exercised for determination of maximum stresses from breakouts and more reliable methods are required than those currently used.
\end{abstract}

\section{Introduction}

In-situ stresses play an important role in subsurface geologic processes in the short-term and long-term. They control rock and fluid movements and pressures, which in turn influence gas, oil and water movements and their production from boreholes. It is therefore of crucial importance to have a good knowledge of the prevailing in-situ stress impacting subsurface zones of interest and to understand the geodynamic processes in order to manage geological reservoirs and underground storage sites (Heidbach et al., 2018). At a certain depth, in-situ stresses consist of three mutually orthogonal com- ponents so called vertical $\left(S_{v}\right)$, minimum horizontal $\left(S_{h \min }\right)$ and maximum horizontal stress $\left(\mathrm{S}_{H \max }\right)$ (Peng and Zhang, 2007). Obviously, drilling induces stress concentrations around the wellbore which may end up with instabilities such as tensile fractures, breakouts and formation collapse (typically in shales). Wellbore breakouts describe a phenomena in which the borehole diameter increases due to the shear failure of the rock formation being penetrated during drilling and are responses to the compressive stress field in the vicinity of the wellbore (Gough and Bell, 1982).

The magnitude and orientation of the in-situ stresses have a direct effects throughout the wellbore during drilling, well

\section{Yandy Scientific} Press
${ }^{*}$ Corresponding author.

E-mail address: Mohammadali.Faraji@uon.edu.au (M. Faraji); reza.gholilou@curtin.edu.au (A. Rezagholilou); m.qanavati1@gmail.com (M. a Ghanavati); kadkhodaie_ali@tabrizu.ac.ir (A. Kadkhodaie); dw@dwasolutions.com (D.A. Wood). 2207-9963 (C) The Author(s) 2021.

Received October 27, 2020; revised November 19, 2020; accepted November 19, 2020; available online November 24, 2020. 
completion and production, and need to be considered by reservoir production simulations (Moos and Zoback, 1990). Jeanne et al. (2016) emphasized that understanding in-situ stresses is of paramount importance when assessing the geomechanical stability of fault zones. Therefore, it is important to characterize and quantify the in-situ stresses as part of geomechanical model development. The comprehensive study of well $\operatorname{logs}$ is typically able to provide vital information with which to determine the in-situ stresses in the vicinity of the wellbore, especially in tectonically active areas.

Several analytical approaches have been developed to determine the minimum and maximum subsurface horizontal stresses (Haimson and Cornet, 2003; Zoback et al., 2003; Fjar et al., 2008). Such methods are primarily based on elastic properties derived from compressional and shear wave travel times. During drilling, in order to form a tension fracture, minimum horizontal stress needs to be more than pressure difference between the mud and the formation being penetrated by the drill bit. In practice, minimum horizontal stress can be obtained from formation leak off tests and extended leak off tests, hydraulic fracturing and mini-frac tests and also mud loss data (Zoback et al., 2003). These methods are feasible for evaluating stresses within limited depth intervals but are very costly and time consuming. However, the determination of $\mathrm{S}_{H \max }$ is more challenging because there is no direct experimental test that can be performed to determine it. $\mathrm{S}_{H \text { max }}$ can be estimated analytically based on breakout widths and/or the strengths of intersecting conjugate shear planes (Zoback et al., 2003; Zoback, 2010; Lin et al., 2020b).

Borehole breakouts and drilling-induced fractures at shallow depths, in the absence of seismic data, are important sources of information for horizontal stress identification. Indeed, about fifteen percent of stress orientations referred to in the world's stress map have been determined based on breakout information of various quality acquired from borehole images (Heidbach et al., 2018). Moreover, a large amount of stress orientation information in the petroleum industry come from drilling-induced fractures associated with breakouts. These features are prevalent in most of oil and gas wells and can be utilized to determine the stress orientations over a range of depths. Information about these features is captured in image logs and it has been used for several decades to determine in-situ stress orientations (Nie et al., 2013; Zhang et al., 2018). Breakouts result from a complex compressional failure when the maximum hoop stress around the well exceeds the rock strength (Zoback, 2010). Tectonic regime and the ratio of $S_{H \text { max }} / S_{h \text { min }}$ influence the breakout or drilling-induced fracture azimuth. However, breakouts tend to occur at the azimuth of the minimum horizontal stress when well deviation is less than $10 \mathrm{deg}$ in normal faulting system (Barton et al., 1988). This special stress status for occurrence of breakouts makes them a possible source for estimating the in-situ stress magnitude. In this regard, different approaches have been proposed to relate breakout information to in-situ stress magnitudes (Zoback et al., 1985; Haimson and Herrick, 1986; Zheng et al., 1989; Vernik and Zoback, 1992; Haimson and Chang, 2002). The most common method applied was introduced by Barton et al. (1988) to estimate the magnitude of maximum horizontal stress directly from measurements of breakout width and geomechanical properties using Eq. (1).

$$
S_{H \max }=\frac{\left(U C S+2 P_{p}+\Delta P\right)-S_{h \min }\left(1+2 \cos 2 \theta_{b}\right)}{1-2 \cos 2 \theta_{b}}
$$

where $\theta_{b}=$ breakout width; UCS $=$ uniaxial compressive strength $(\mathrm{MPa}) ; P_{p}=$ pore pressure $(\mathrm{MPa}) ; \Delta P=$ the difference between mud pressure and pore pressure $(\mathrm{MPa})$; and, $S_{h \min }=$ minimum horizontal stress.

A key limiting assumption of the "Barton" equation (Eq. (1)) is that all breakouts are assumed to occur in a horizontal plane. The equation is, therefore, only accurate when failure types are developed exactly normal to the vertical wellbore axis. However, stability analysis of many vertical wellbores has proved that shear failures can occur in different shapes and at angles other than normal to the borehole axis (AlAjmi and Zimmerman, 2006; Pašić et al., 2007). Lin et al. (2020a) highlighted another drawback of the Barton's equation via comparing breakout geometries with different hole sizes. They revealed that larger hole size tends to yield deeper and wider breakouts; yet such effects are not considered by Barton's equation. Moreover, a number of researchers have argued that it is not possible to obtain two horizontal stress magnitudes from breakouts, as one parameter cannot estimate two horizontal stresses (Haimson and Lee, 2004; Sahara et al., 2017).

The aim of this study is to examine the reliability of maximum horizontal stress derived from breakout width by comparing the results of different methods, and also analysing the failure types. Rasouli et al. (2013) applied the elastic approach and analysed the in-situ stress in the GSWA Harvey1. The data from the GSWA Harvey-1 well is further evaluated here to establish the reliability of breakout data for in-situ stress estimation. Different methods proposed for the estimation of in-situ stress are compared and detailed evaluations are elaborated including stress polygons to characterize the likely shear-failure (breakout) types involved. To do so, a short review of the geologic setting of the GSWA Harvey1 well is presented, followed by the development of a onedimensional model describing breakouts in geomechanical terms. The maximum horizontal stress is then determined based on different methods and a comparison of their results is provided to discuss the reliability of each method.

\section{GSWA Harvey-1}

The GSWA Harvey-1 (hereafter referred to as Harvey-1) well is located in the southwestern part of Australia, onshore Southern Perth Basin in the Shrine of Harvey region (Fig. 1). The Perth Basin extends northerly along the southernmost 700 $\mathrm{km}$ of the western coast of Australia. Evolution of the basin began at the end of the Carboniferous or in the Early Permian following a north-trending regional rifting episode. The intensity of rifting varied considerably, thus the sedimentation rates and formation thicknesses varied locally (Crostella and Backhouse, 2000). However, a Permian to Holocene succession overlying Precambrian basement is present throughout the basin. The well Harvey-1 was drilled to a total depth of 2,945 


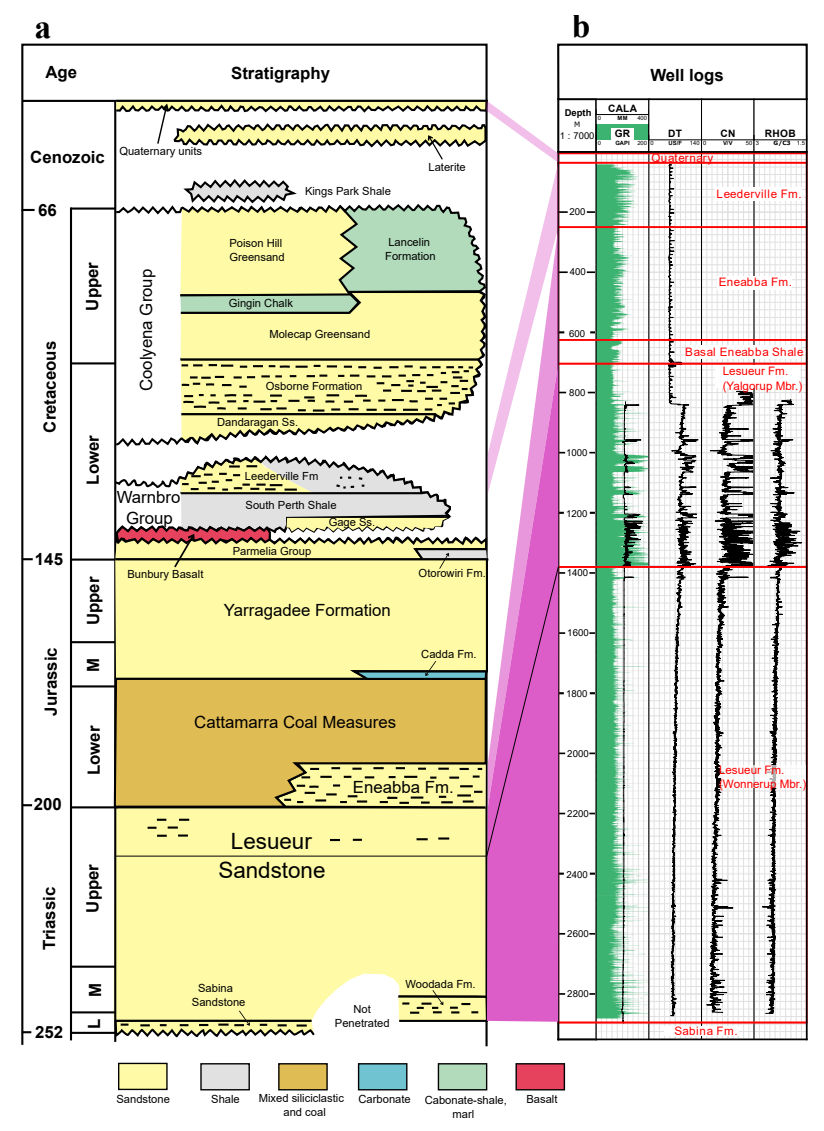

Fig. 1. Location map of GSWA Harvey-1 well.

$\mathrm{m}$ as a stratigraphic well test on a structural feature known as the Harvey Ridge trending northwest to southeast. The primary objective of the well was to determine the suitability of subsurface formations for the injection and storage of carbon dioxide produced from nearby facilities. The information from the well has also been exploited to evaluate the geothermal energy and petroleum potential of the formations penetrated.

In terms of stratigraphy (Fig. 2), the lower Triassic Sabina Sandstone, composed of medium to coarse-grained sandstone with minor shale, is the oldest formation penetrated by Harvey1 (Millar and Reeve, 2014). The Lesueur Sandstone, of middle-to-late Triassic age, conformably overlies the Sabina formation and is itself overlain by the Eneabba formation. With respect to its good porosity and permeability development, based on the petrophysical evaluation, and its suitable depth range for $\mathrm{CO}_{2}$ storage (greater than $800 \mathrm{~m}$ ), this formation is considered as a potential reservoir.

The lower Lesueur (Wonnerup member) is a homogeneous, poorly sorted sandstone displaying fine to coarse grain sizes. The upper Lesueur sandstone (Yalgorup member) is characterized by subordinate interbeds of claystone/siltstone that can be up to $20 \mathrm{~m}$ thick and sometimes multi-coloured. This Triassic interval is overlain by the Eneabba Formation of lower Jurassic age, consisting of coarse- to very coarse-grained sandstones interbedded with local minor conglomerates and multi-coloured claystones and siltstones. This thick formation with a wide spread presence of fine-grained clastics represents a potential cap rock that can hinder the migration of injected gas. The Leederville formation overlies the Eneabba with an unconformity between them. It consists of interbedded sandstones, shales and conglomerates. The undifferentiated Quaternary sediments consisting of clays and minor gravelly sand are the youngest beds penetrated by the wellbore (Millar and Reeve, 2014). Fig. 2 shows the stratigraphic units of well Harvey-1 well providing lithological descriptions of main formations. Gamma ray (GR), caliper (CALA), acoustic interval transit time (DT), neutron porosity $(\mathrm{CN})$, and formation bulk density (RHOB) well logs are also presented in this figure.

From the breakout perspective, these features are well developed throughout the Yalgorup member of Lesueur formation and in limited intervals of Wonnerup, thus the former is main focus of this study. The considerable occurrence of breakouts along with the availability of a reasonably comprehensive geological and geomechanical dataset, are the main reasons that Harvey-l has been selected for determination of $\mathrm{S}_{H \max }$ in this study.

\section{Methodology}

The methodology of this study follows two main steps: (1) estimation of geomechanical properties; and, (2) evaluation of image logs and the determination of maximum horizontal stress and failure types. The results of step 2 are then compared as part of a detailed discussion on the reliability of breakoutsderived maximum horizontal stress. 


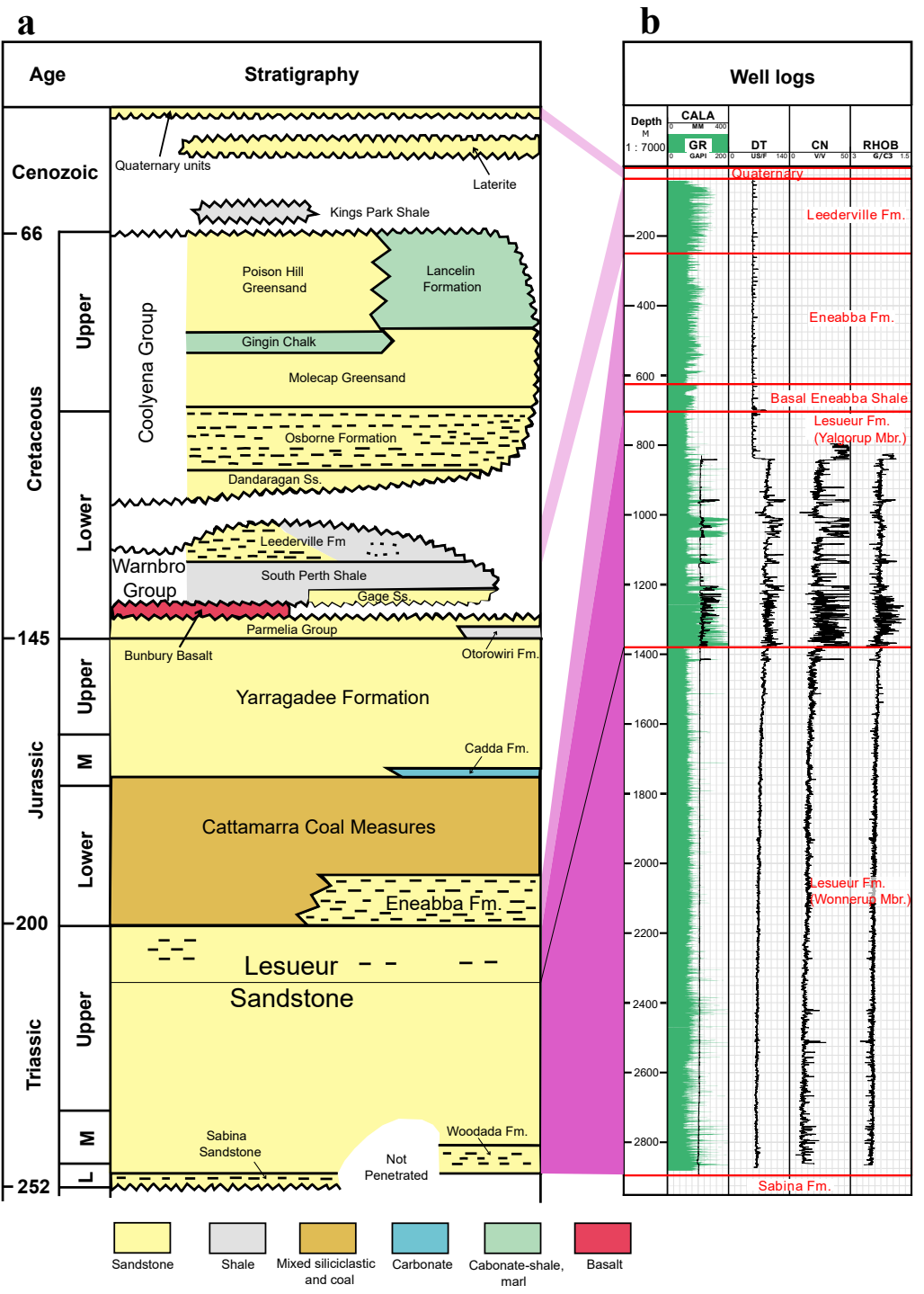

Fig. 2. a: General stratigraphic units of southern Perth Basin where Harvey-1 well is located (after Millar and Reeve, 2014); b: log measurements of gamma ray (GR), caliper (CALA), acoustic interval transit time (DT), compensated neutron (CN) and bulk density (RHOB) measurements. Caliper readings show the wellbore widening towards the bottom of the Yalgorup member, where the majority of breakouts occurred. The well's end depth is located in the lower Triassic Sabina sandstone.

Initially, the rock elastic parameters and in-situ stresses are assessed via the interpretation of image logs from the well Harvey-1. Various likely shear failures throughout the well were identified from the available well $\operatorname{logs}$ as suitable for determining horizontal stresses. A full suite of well logs were recorded for the Harvey-1 well. These include bit size, caliper, compensated neutron porosity, acoustic interval transit time, gamma ray, shallow and deep resistivity, mud resistivity, formation bulk density, the Circumferential Borehole Imaging Log (CBIL) and high-resolution resistivity formation images. The CBIL image logs for Harvey-1 cover the depth interval 840 to $2,732 \mathrm{~m}$. The only available Formation Integrity Test (FIT) recorded $20.5 \mathrm{ppg}$ at a depth of $848 \mathrm{~m}$ and it is used to calibrate the minimum horizontal stress. Fig. 3 shows a depth interval from the CBIL. Prior to any calculations, environmental corrections were applied, a conventional data quality control analysis performed, and outlier data removed from all well logs. The quality-controlled image log data was then processed and interpreted.

\subsection{One-dimensional rock mechanical model}

A One-dimensional (1D) geomechanical model is constructed along the wellbore based on conventional well data and is used to represent the mechanical properties and stress states the near-borehole vicinity. This model investigates rock mechanical behaviour around the wellbore including breakouts, loss, sand production, and also stability of well (Ranjbar et al., 2017). A typical rock mechanical model consists of elastic modules (Young's, bulk and shear modulus, Poisson's ratio), strength indicators (UCS, tensile strength, internal friction angle, cohesion), in-situ stresses (vertical, maximum and minimum horizontal stresses), and pore pressure. Some of these parameters are integrated here into a $1 \mathrm{D}$ rock mechanical model for Harvey-1, which will be later used to determine the 


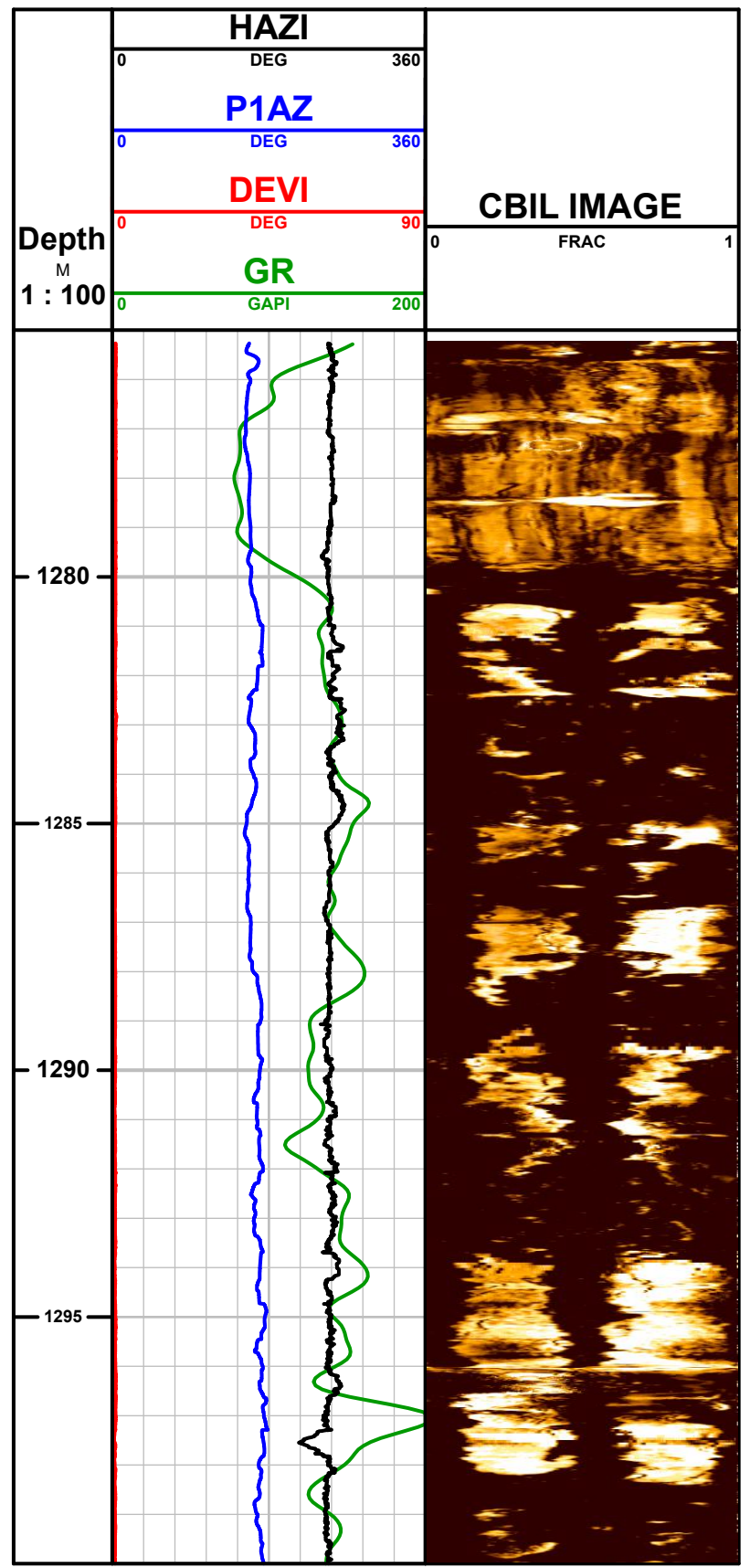

Fig. 3. A short interval of the well Harvey-1 with CBIL image coverage. GR is gamma ray, DEVI is borehole deviation, P1AZ is the angle between borehole azimuth and reference pad azimuth and HAZI is borehole azimuth.

magnitude of horizontal stresses. This model includes elastic modules and strength parameters.

In order to determine elastic parameters of rock formations penetrated by wellbores, compressional and shear wave velocities combined with bulk density data of the subsurface layers are required (Zoback et al., 2003; Fjar et al., 2008; Archer and Rasouli, 2012). Elastic parameters are of importance in geomechanics as they provide useful assessments of wellbore stability and reservoir characterization (Tixier et al., 1975; Farquhar et al., 1994; Bastos et al., 1998; Edimann et al., 1998; Faraji et al., 2017). The Eqs. (2)-(9) are used to calculate elastic parameters and construct the geomechanical model from well logs.

$$
E_{d y n}=\left(\frac{\mathrm{RHOB}}{\Delta t_{s}^{2}}\right)\left(\frac{3\left(\Delta t_{s}^{2}\right)-4\left(\Delta t_{p}^{2}\right)}{\Delta t_{s}^{2}-\Delta t_{p}^{2}}\right) * 1.34 * 10^{10}
$$

where $E_{d y n}$ is the dynamic Young's modulus in psi; RHOB is rock bulk density in $\mathrm{g} / \mathrm{cc}$, and $\Delta t_{s}$ and $\Delta t_{p}$ are shear and compressional wave transit times in $\mu \mathrm{s} / \mathrm{ft}$. Core test results for Harvey-1 have shown a linear relationship between shear wave velocity $\left(V_{s}\right)$ and compressional wave velocity $\left(V_{p}\right)$ as $V_{s}=0.5986 * V_{p}-0.1082$ (Delle Piane et al., 2013). This relationship is used here to calculate $\Delta t_{s}$ values from the 
available sonic $\log \left(\Delta t_{p}\right)$.

$$
\begin{gathered}
G_{d y n}=\left(\frac{\mathrm{RHOB}}{\Delta t_{s}^{2}}\right) * 1.34 * 10^{10} \\
K_{d y n}=\operatorname{RHOB}\left(\frac{1}{\Delta t_{p}^{2}}-\frac{4}{3 \Delta t_{s}^{2}}\right) * 1.34 * 10^{10}
\end{gathered}
$$

where $G_{d y n}$ is dynamic shear modulus and $K_{d y n}$ is dynamic bulk modulus, both in psi.

$$
v_{d y n}=\frac{V_{p}^{2}-V_{s}^{2}}{2\left(V_{p}^{2}-V_{s}^{2}\right)}
$$

where $v_{d y n}$ is dimensionless dynamic Poisson's ratio; and, $V_{p}$ and $V_{s}$ are in $\mathrm{m} / \mathrm{s}$.

These dynamic values are converted to static values using Eqs. (6)-(8) (Archer and Rasouli, 2012). There is a difference between dynamic and static elastic parameters which is related to the type of data that is used to acquire them. A dynamic modulus is derived from a travelling acoustic wave with a frequency of a few kilohertz, perturbing the material at a constant stress, whereas a static modulus is derived from laboratory tests performed at extremely low rates of stress change but over a much larger stress range (Ali et al., 2003). Thus, the following empirical equations are employed to make the conversion between dynamic and static values.

$$
\begin{gathered}
E_{\text {sta }}=0.04145 E_{\text {dyn }}-1.0593 \\
G_{\text {sta }}=\frac{E_{\text {sta }}}{2\left(1+v_{\text {sta }}\right)} \\
K_{\text {sta }}=\frac{E_{\text {sta }}}{3\left(1-2 v_{\text {sta }}\right)}
\end{gathered}
$$

The static and dynamic Poisson's ratio are assumed to be equal.

The friction angle $(\phi)$ was calculated based on Plumb (1994)'s correlation by Eq. (9):

$$
\begin{aligned}
\phi= & 26.5-37.4\left(1-\text { porosity }-V_{\text {shale }}\right) \\
& +62.1\left(1-\text { porosity }-V_{\text {shale }}\right)^{2}
\end{aligned}
$$

where the $V_{\text {shale }}$ is volume $(\mathrm{v} / \mathrm{v})$ of shale derived from gamma ray $\log$, and porosity is neuron porosity $(\mathrm{v} / \mathrm{v})$.

\subsection{Determination of $S_{H \max }$ and wellbore rock failure types}

Image logs are valuable sources of information for the subsurface layers and different geo-structural features penetrated by wellbores. Interpretations of image-log data can be used to determine natural and induced fractures, sedimentary and stratigraphy structures, sedimentary bedding, structural dips and other geometric characteristics (Höcker et al., 1990; Luthi, 2001; Pppelreiter et al., 2005; Xu et al., 2006; Xu, 2007; Tingay et al., 2008; Folkestad et al., 2012).

In the current study the acoustic CBIL for an interval in well Harvey-1 was processed applying logging-speed corrections, equalization, normalization and other processing steps to improve the resolutions of its images. The processing began by applying checks and corrections for abrupt changes in logging-tool speed during recording. It proceeded with equalization, in which the average response of all the receivers of the tool are rendered approximately the same over large intervals. Normalization involves transformation of equalized data into a normal distribution in an attempt to maximize the amount of information derived from the recorded signal. On completion of these steps, the processed image can be displayed in two main formats: static and dynamic. The former is acquired by applying a colour range to the whole depth interval evaluated. The latter is generated by applying a colour range to each 1-2-inch-wide moving window from top to the bottom. The detailed processing steps for image logs are provided by Farag et al. (2010) and Hurley and Zhang (2011). In these processed formats, the CBIL data can be interpreted for breakouts and to determine the parameters associated with drilling-induced fractures, such as azimuth and strike direction measured throughout the well. Specifically, Eq. (1) can then be applied to estimate the maximum horizontal stress based upon breakout widths. Such calculations were performed on processed CBIL data from the Harvey-1 well.

In addition, the poroelastic Eqs. (10)-(11) were used for the estimation of in-situ stresses in order to make comparison with stress estimates obtained by other methods.

$$
\begin{aligned}
& S_{H \max }=\frac{v}{1-v}\left(S_{V}-\alpha P_{p}\right)+\alpha P_{p}+\frac{E \varepsilon_{x}}{1-v^{2}}+\frac{v E \varepsilon_{y}}{1-v^{2}} \\
& S_{h \min }=\frac{v}{1-v}\left(S_{V}-\alpha P_{p}\right)+\alpha P_{p}+\frac{E \varepsilon_{y}}{1-v^{2}}+\frac{v E \varepsilon_{x}}{1-v^{2}}
\end{aligned}
$$

where $\varepsilon_{x}$ and $\varepsilon_{y}$ are iterative estimates tectonic strains, $v$ is Poisson's ratio (dimensionless), $S_{v}$ is vertical stress (MPa), $\alpha$ is Biot factor and $E_{\text {sta }}$ is static Young's modulus (MPa). The Biot factor was calculated as a function of porosity from the Eq. (12) (Farrokhrouz and Asef, 2012).

$$
\alpha=1-e^{(-3.8 \varphi-0.86)}
$$

Reliable values for tectonic strains require solving of Eq. (10) for at least two $S_{h \min }$ values. When there is only one test result for $\mathrm{S}_{h \min }$, as is the case for Harvey 1 with one FIT at 848 meters, an iterative method can be used. The iterative method is based on making various assumptions for $\varepsilon_{x}$ and $k=\varepsilon_{y} / \varepsilon_{x}$ until the $\log$ values for maximum tangential stress and caliper show a good match. Tectonic strains from this method are approximations and there may be more than one solution that fits the data.

The Blanton and Olson (1999)'s approach has also been implemented here to calculate tectonic strain (Eq. 13). This method employs elastic and plain strain condition along the wellbore. Tectonic strain is set zero in one direction to obtain differential strain in the perpendicular direction. As such, there is no potential calibration error for this method.

$$
\varepsilon_{t e c t}=\frac{S_{h \min }-C_{2}}{C_{1}}
$$


where $C_{1}$ and $C_{2}$ are calculated based on Young's modulus, Poisson's ratio and vertical stress (Blanton and Olson, 1999).

Furthermore, to provide an additional comparison, Eq. (14) proposed by Kidambi and Kumar (2016) has also been also applied to estimate tectonic strain components ( $\varepsilon_{x}$ and $\varepsilon_{y}$ ).

$$
\begin{aligned}
& \varepsilon_{x}=\frac{S_{V} * v}{E}\left(\frac{1}{1-v}-1\right) \\
& \varepsilon_{y}=\frac{S_{V} * v}{E}\left(1-\frac{v^{2}}{1-v}\right)
\end{aligned}
$$

Table 1 provides the gradient ranges of principal stresses, based on comprehensive stress regime studies for the Perth Basin conducted by King et al. (2008). $\mathrm{S}_{H \max }$ magnitudes derived from elasticity metrics make it possible to evaluate $\mathrm{S}_{H \text { max }}$ effectively from breakouts data, regardless of inherent inaccuracies associated with breakout widths measurements, rock failure plane orientations and other parameters involved in Eq. (1). To assess the potential impacts of these inaccuracies on the stress estimates, stress polygons are essential for visualizing the likely ranges of in-situ stress estimates derived from the different methods. For that reason, stress polygons of Harvey-1 are developed for the depth intervals where breakouts exist.

Table 1. The gradient ranges of principal stresses in the Perth Basin (King et al., 2008).

\begin{tabular}{ll}
\hline Principal Stress & Gradient $(\mathrm{MPa} / \mathrm{km})$ \\
\hline $\mathrm{S}_{H \max }$ & $21.3-21.75$ \\
$\mathrm{~S}_{h \min }$ & $18.5-26.25$ \\
$\mathrm{~S}_{v}$ & 21.5 \\
\hline
\end{tabular}

Any inconsistency or discrepancy of $\mathrm{S}_{H \max }$ results might be attributed to different rock properties, shear failure criteria and breakouts types. Differences due to rock properties and various failure criteria models, such as Mohr-Colomb theory, are ignored for the purpose of the evaluations conducted here. As noted, drilling a borehole changes the pattern of uniform stresses and concentrates them around the wellbore. In a linear elastic material, the borehole wall copes with high stresses up to appoint, beyond which failure is likely to occur. As such, wellbore instability analyses rely upon comparisons of these stresses with a failure criteria model. The stresses in a vertical well, such as Harvey-1 is, can be formulated using Eqs. (16)(18) based on the Kirsch solution (Hudson et al., 2002). Employing the Kirsch equations is important to calculate the stress level around the borehole, which can further help to determine the loading on the borehole wall. Each type of failure occurs under a specific stress configuration, thus, in order to define the failure types, it is essential to understand the stresses around the borehole. Failure types are then used to investigate if the failures occurred on a horizontal plane.

$$
\sigma_{r}=P_{w}
$$

$$
\begin{gathered}
\sigma_{\theta}=S_{H \max }+S_{h \min }-2\left(S_{H \max }-S_{h \min }\right) \cos 2 \theta-P_{w} \\
\sigma_{z}=S_{V}-2 v\left(S_{H \max }-S_{h \min }\right) \cos 2 \theta
\end{gathered}
$$

where $\sigma_{r}$ is the radial stress, $\sigma_{\theta}$ is the tangential stress, $\sigma_{z}$ is the axial stress, $P_{w}$ is the internal wellbore pressure, and $v$ is the Poisson's ratio of the rock. Since the radial stress is not related to $\theta$, it is the same in all directions and determines well pressure. Well pressure and tangential stress are inversely proportional. Table 2 shows the minimum and maximum allowable mud pressure in order to prevent rock failure based on the Mohr-Coulomb criterion. This is the simplest and most commonly used criterion for brittle failure of rocks and involves only the maximum and minimum principal stresses. It therefore assumes that the intermediate stress has no influence on rock strength (Al-Ajmi and Zimmerman, 2006). Numerous researchers have pointed out that this criterion is expected to be too conservative in estimating the critical mud pressure required to maintain a stable wellbore (Mogi, 1971; Takahashi and Koide, 1989; Haimson and Chang, 2002). However, as there is no information available on the intermediate stress for Harvey-1, we have used the Mohr-Coulomb criterion in this study.

\section{Results and discussion}

In the current study, rock elastic constants have been derived from well logs. Fig. 4 illustrates the calculated parameters along with a three-dimensional (3D) view of the studied image log across a specific depth range of the Harvey-1 well. Breakouts can be seen in this figure as enlargements in the image radius. The histogram and box plot of calculated elastic moduli are presented in Fig. 5. It is apparent that the elastic data follow complex bimodal distribution functions with two distinct overlapping peaks that according to boxplots are responding to two distinct lithology types: clay/silt which dominates in the Yalgorup member and sandstone which dominates in Wonnerup member. Sandy lithologies are associated with higher strength and related to the higher elastic moduli peak. The entire CBIL images are then interpreted with these assumptions and the breakouts identified and the properties of the associated induced fractures measured. The logic behind these image logs which makes the interpretation of these rock failures possible is the contrast between the intact and failed parts of the wellbore walls. This contrast is recordable by detecting differences between amplitude and/or travel times in the acoustic logs, and between resistivity values in electrical tools.

For the Harvey-1 case, breakouts with less density compared to the neighbouring higher density of relatively intact rocks distinguish two contrasting wellbore regions. As a result of such density variations, the travel time of acoustic waves transmitted through these two zones is substantially different. Breakouts show a longer travel time and lower acoustic amplitude in comparison to the non-fractured zones of the wellbore walls. By applying a colour scale in which breakouts are depicted in brighter colours, the interpretation 
Table 2. Minimum and maximum allowable mud pressure to prevent rock failure (Al-Ajmi and Zimmerman, 2006).

\begin{tabular}{lll}
\hline Failure will occur if: & $\sigma_{1} \geq \sigma_{2} \geq \sigma_{3}$ & Failure type \\
\hline$P_{w} \leq(A-C) /(1+q)$ & $\sigma_{\theta} \geq \sigma_{z} \geq \sigma_{r}$ & Shear Failure Wide Breakout \\
$P_{w} \leq(B-C) / q$ & $\sigma_{z} \geq \sigma_{\theta} \geq \sigma_{r}$ & Shear Failure Shallow Knockout \\
$P_{w} \geq(C-E) /(q+D)$ & $\sigma_{z} \geq \sigma_{r} \geq \sigma_{\theta}$ & Shear Failure High-Angle Echelon \\
$P_{w} \geq(C+q D) /(1+q)$ & $\sigma_{r} \geq \sigma_{z} \geq \sigma_{\theta}$ & Shear Failure Narrow Breakout \\
$P_{w} \geq(C+q E)$ & $\sigma_{r} \geq \sigma_{\theta} \geq \sigma_{z}$ & Shear Failure Deep Knockout \\
$P_{w} \leq(A-C-q B)$ & $\sigma_{\theta} \geq \sigma_{r} \geq \sigma_{z}$ & Shear Failure Low-Angle Echelon \\
\hline$A, B, D, E$ and $q$ were defined as: $A=3 S_{H \max }-S_{h \min }, B=S_{V}+2 v\left(S_{H \max }-S_{h \min )}, D=3 S_{h \min }-S_{H \max }, E=S_{V}-2 v\left(S_{H \max }-S_{h \min }\right)\right.$ \\
\hline
\end{tabular}

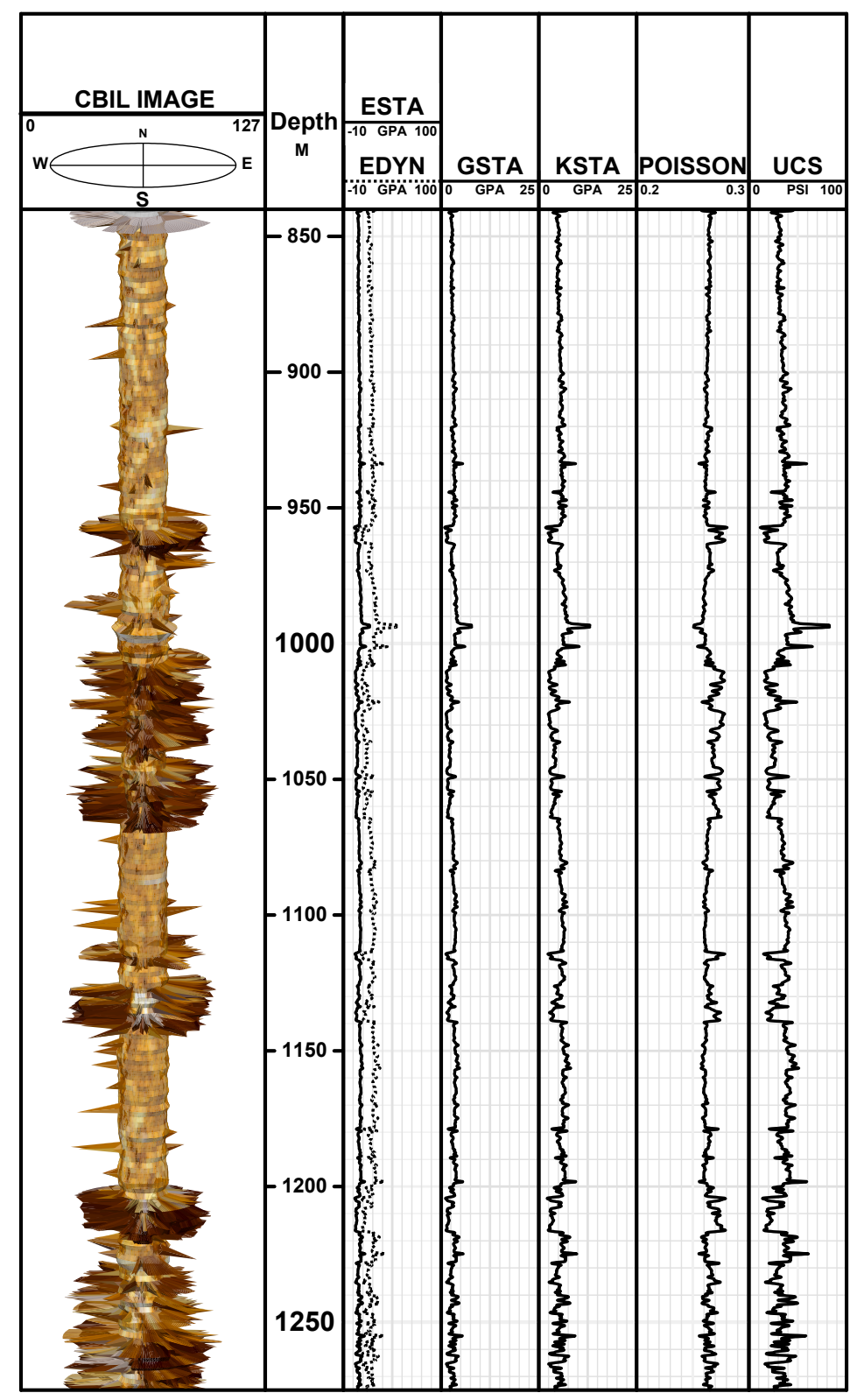

Fig. 4. Rock mechanical model of Harvey-1. Calculated elastic moduli along with a 3D view of CBIL image including breakouts. In this figure ESTA is static Young's modulus, EDYN is dynamic Young's modulus, GSTA is static shear modulus, KSTA is static bulk modulus and UCS in uniaxial compressive strength. 

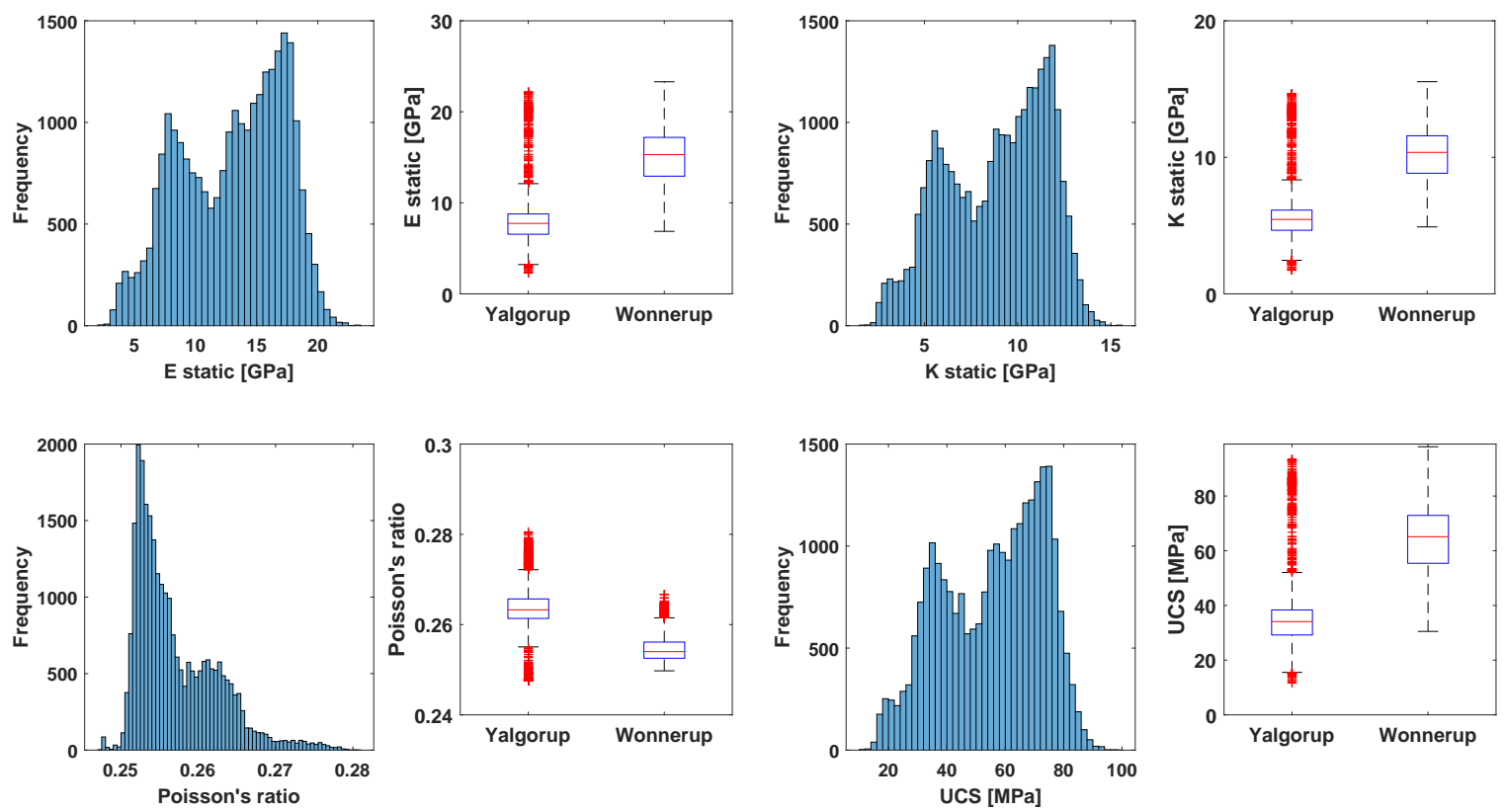

Fig. 5. Histogram and boxplots of static elastic moduli in the Lesueur formation. These all show bimodal skewed distributions with two main concentrations distinguished by lithology. The boxplots indicate the variations in the rock strength due to lithological contrast between the Yalgorup and Wonnerup members with the latter being of higher strength.

and characterization of the breakout zones is simply visualized. Width and azimuth of breakouts are then measured within each recorded depth interval. Fig. 6 illustrates an interpreted depth interval of the studied well. Dip azimuth and strike direction of an example recorded breakout are also shown in Fig. 6. The strike direction of these breakouts is $\mathrm{N} 10 \mathrm{E}$, which is roughly perpendicular to the direction of $\mathrm{S}_{H \max }$ around the wellbore and the trend of the Harvey Ridge. The mean dip azimuth of the identified breakouts is about 10 degrees. It can therefore be concluded that the maximum horizontal stress is oriented parallel to the mean dip azimuth at 99 degrees. The azimuth and strike directions of the breakouts for the entire Harvey1 depth interval studied is plotted on the Schmidt rose nets in Fig. 7. The direction of maximum and minimum horizontal stresses can be inferred from this figure. The orientation of the minimum horizontal stress is equal to the strike direction of the breakouts and the maximum stress is normal to the minimum stress and parallel to the dip azimuth of the breakouts.

Fig. 8 displays the histogram, statistical information and box plot of breakouts widths. The widths of the breakouts reveal a bimodal complex distribution, apparently consisting of two overlapping normal distributions, with most values located between 30 and 130 degrees. According to the boxplot in Fig. 8, the breakouts in clay/silt-bearing Yalgorup member demonstrate a wider width compared to sandy Wonnerup member. Considering this wide range of breakout widths and the physical constraint that breakout width cannot exceed the 90 degree, because, if it did, the wellbore would not remain stable, it can be concluded that the breakouts identified with widths greater than 90 degree should be regarded as highly uncertain. If just the smaller range of breakout widths, between 30 to 90 degree, is considered, it still leads to a potentially wide range of calculated $\mathrm{S}_{H \text { max }}$ values.
Fig. 9 illustrates the calculated values for $S_{H \max }$ derived from three different poroelastic methods (Blanton and Olson, 1999; Fjar et al., 2008; Kidambi and Kumar, 2016) with those derived from breakout analysis (Barton et al., 1988). We have assigned the name "poroelastic" to the Fjar et al. (2008)'s method in which tectonic strains are derived from the leakoff test. As shown in Fig. 9, although there is an increasing trend with depth for $\mathrm{S}_{H \text { max }}$ in all methods, the values derived from breakout analysis (Barton's method) are not in agreement with the values derived from the three poroelastic methods. The values of breakout-derived $\mathrm{S}_{H \text { max }}$ are much greater than values derived by other three methods. Since the results of $S_{h \min }$ for all poroelastic methods are close to each other, and also considering the fact that poroelastic methods have a sound and logical mathematical foundation, particularly the (Blanton and Olson, 1999)'s approach, such a big difference between $\mathrm{S}_{H \max }$ values is not considered to be reasonable. The scattered pattern of breakouts- $\mathrm{S}_{H \text { max }}$ values is likely related, at least in part, to the wide range and large standard deviation of breakouts widths (Fig. 8). Fig. 9 demonstrates how tectonic strains are also apparently affecting calculated results for both $\mathrm{S}_{H \max }$ and $\mathrm{S}_{h \min }$.

The three poroelastic methods provide stress estimates showing some systematic differences, particularly for deep intervals. The differences between the poroelastic stress estimate curves increase as a function of depth. This is likely caused by increasing $\varepsilon_{x}$ and $\varepsilon_{y}$ values with depth. Fig. 10 provides histograms and boxplots for $\mathrm{S}_{H \max }$ calculated by the four methods considered. The frequency distribution of estimated $\mathrm{S}_{H \max }$ values based on breakouts (Barton method) appears to be highly dependent on the quality of the image logs and the interpretation of breakout width. In addition, the breakout method is most likely subject to other limitations and/or inac- 


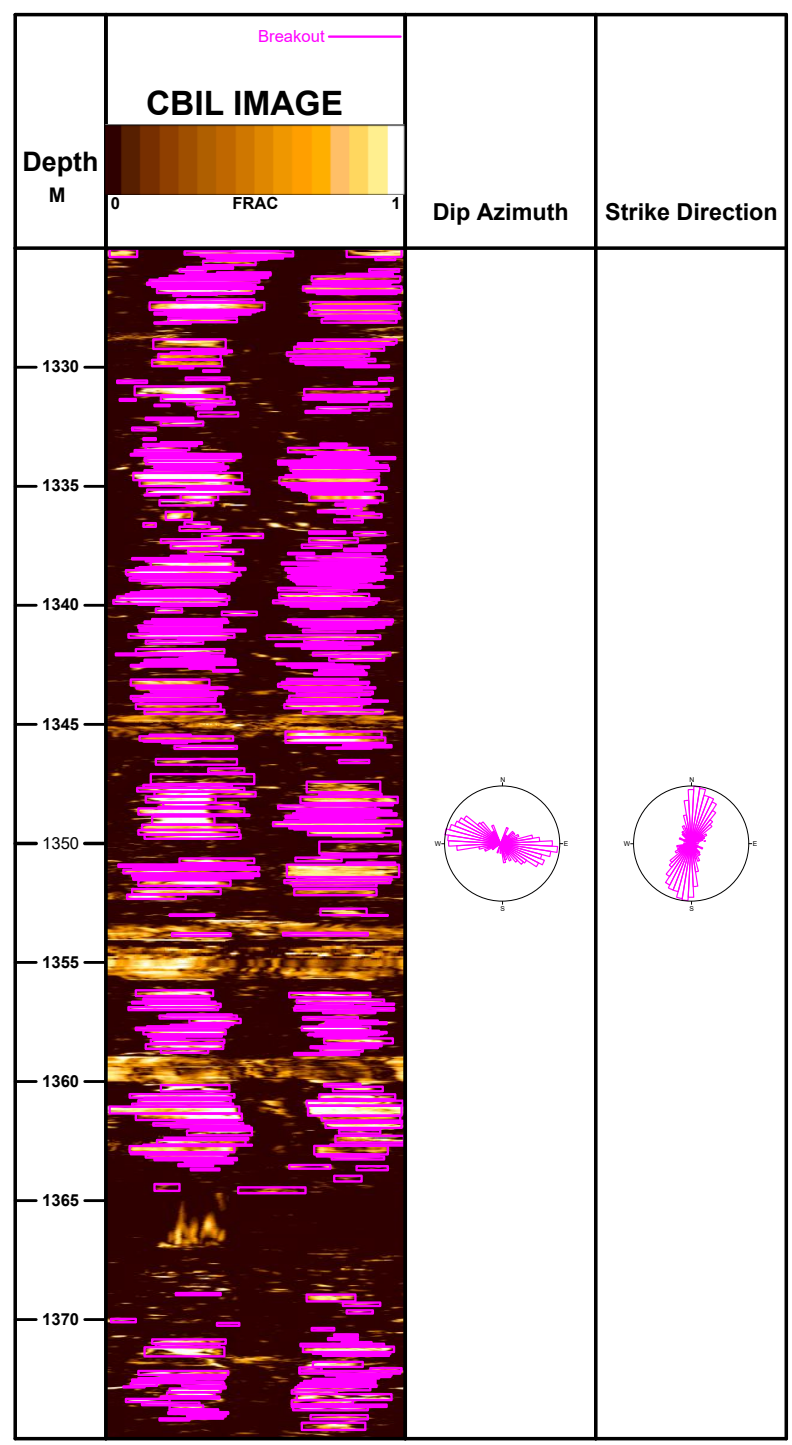

Fig. 6. Breakout width measured on the CBIL image in a specified interval. The purple rectangles overlaying the image log are the picked/interpreted breakouts and the length of each rectangle is equal to the width of breakout at that point. The breakout azimuth and strike direction distributions are also displayed for this interval, the orientation of maximum horizontal stress is coincident with the dip azimuth of the breakouts.
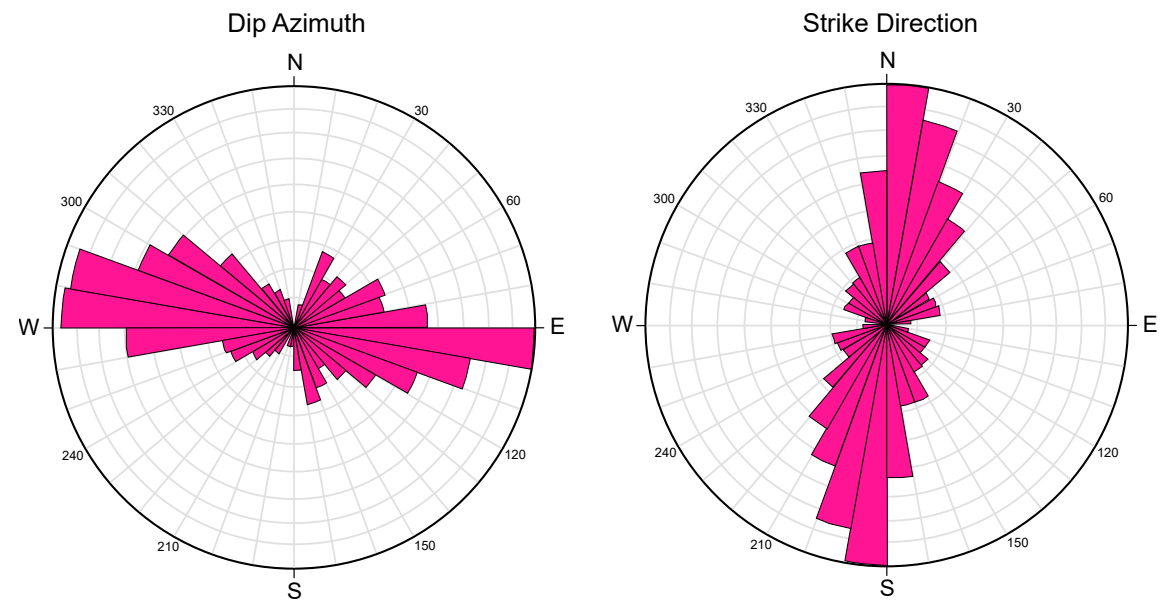

Fig. 7. Schmidt rose net diagrams showing the azimuth and strike direction of measured breakouts in the Harvey-1 well for depth interval 840 to 2,732 meters. The orientation of $S_{h \text { min }}$ is equal to the strike direction of the breakouts $(\approx \mathrm{N} 10 \mathrm{E})$ and $\mathrm{S}_{H \text { max }}$ is normal to the minimum stress and parallel to the dip azimuth of the breakouts $(\approx \mathrm{N} 99 \mathrm{E})$. 

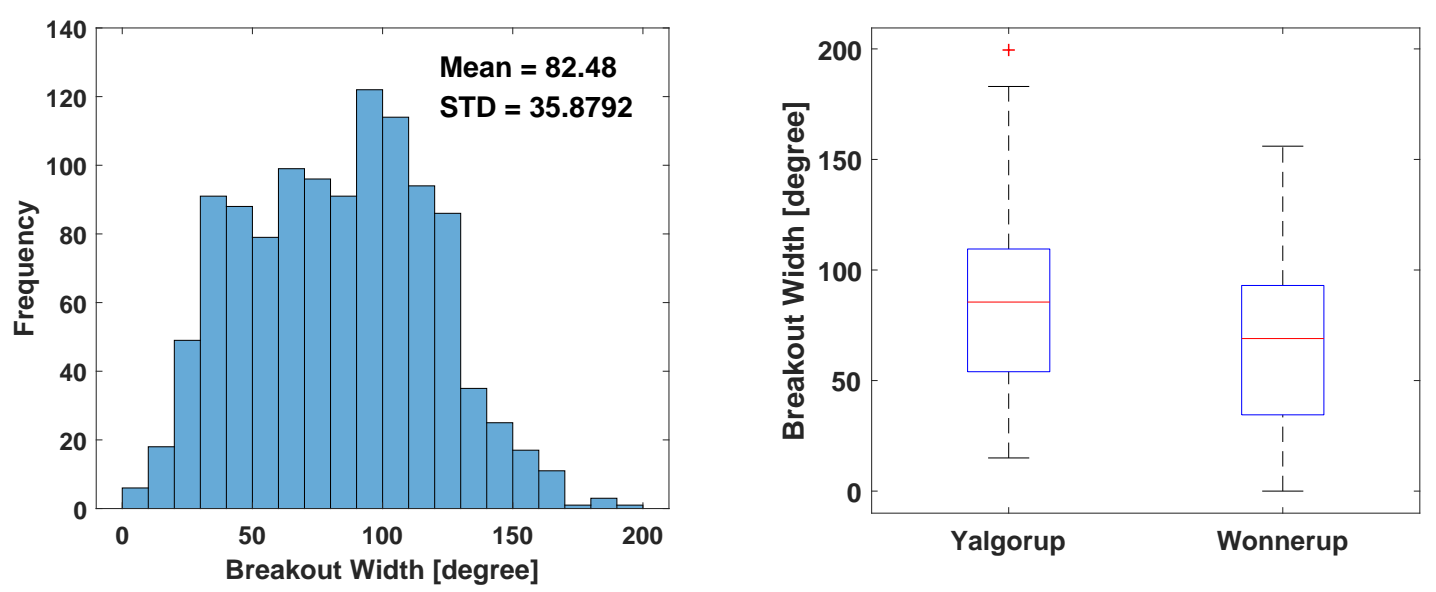

Fig. 8. Histogram and boxplot of interpreted breakouts width. The distribution shows a substantial spread of values from 10 to 150 degrees associated with a large standard deviation. The boxplot illustrates that width of breakouts in Yalgorup with clayey and siltstone intervals is wider than Wonnerup that is dominated by sandstone lithologies.

curacies. Although the higher values of $\mathrm{S}_{H \max }$ for Wonnerup member is mostly because of its greater depth, the values from the Barton method show a wide overlapping range for both the Yalgorup and Wonnerup members. The main assumption for estimation of in-situ stress magnitude from breakouts is that these fractures are horizontal features. However, according to Table 2 and (Pašić et al., 2007), different configurations of stresses around wellbore favour the occurrence of breakouts of different shapes and in oblique planes with angles other than normal to the borehole vertical axis. If that is the case, it is likely to lead to serious inaccuracies in $S_{H \max }$ estimations from breakouts using the Barton method.

The determination of shear-failure using geomechanical models based on the in-situ stresses around well provide different failure-type conditions under which $\mathrm{S}_{H \text { max }}$ estimates can be derived by the poroelastic and breakout methods. By applying the Eqs. (16)-(18) and also the definitions provided in Table 2, different types of wellbore failures for the studied illustrated in Fig. 11. As shown, the three Kirsch, Blanton and Kidambi methods all classify failure types as high angle echelon shear failures, regardless of the differences in $\mathrm{S}_{H \text { max }}$ values among them. In contrast, failure types derived from Barton's $\mathrm{S}_{H \max }$ values are significantly different, where the high-angle echelon is not the only failure and deep knockout, and also narrow breakouts are included in the failures identified. For example, the depth interval of 925 to 975 meters is mostly characterized by narrow breakouts and deep knockout shear failures from the Barton method's point of view, whereas the other methods suggest a high angle echelon shear failure for this interval.

An alternate approach is to construct stress polygons or zobackograms. These are developed for Harvey-1 and illustrated in Fig. 12.These polygons provide valuable information on the state of stress, and their construction is straightforward. Given the fact that $S_{H \text { max }} \geq S_{h \text { min }}$, all possible stress states fall above the diagonal line of unit slope in Fig. 12. The vertical and horizontal lines intersecting at $\mathrm{S}_{H \max }=\mathrm{S}_{h \text { min }}=$ $\mathrm{S}_{v}$ separate the stress fields associated with normal, strike-slip and reverse faulting stress environments (Zoback, 2010).

These polygon are developed for four depth points in Harvey-1 well where breakouts occur. All these points are selected from Yalgorup member of Lesueur formation where most of the breakouts occurred. Table 3 lists the gamma ray values, and also geomechanical characteristics of these points. In terms of lithology, these points fall within claystone and siltstone interbeds of the Yalgorup member. These points are chosen from different depths within the Yalgorup member, such that they provide a reasonable range of lithological and geomechanical variations. The mean width of breakouts is 50 degrees at points $\mathrm{a}, \mathrm{b}$ and $\mathrm{c}$ is and 55 degrees at point $\mathrm{d}$. Point $\mathrm{c}$ is associated with the lowest values for the elastic parameters and is interpreted as the most unstable and damaged point. In contrast, point $\mathrm{d}$ is associated with high rock strength qualities and shows the highest values for the elastic parameters and the lowest Poisson's ratio value.

The developed stress polygons are illustrated in Fig. 12. As such, the possible ranges of horizontal principal stresses at a specific depth, including breakouts effects, are depicted. The stress polygons, as shown in Fig. 12, permit a very wide range of stress values at each specific depth. This limits application in accurately determining stress magnitudes unless some information about the least principal stress is included to narrow the range of $S_{h \min }$. In the Harvey-1 case, in order to draw the polygons, we established the range of $S_{h \text { min }}$ using the assumptions of King et al. (2008), who attempted to define this range based on available leak-off tests from neighbouring wells. Maximum horizontal stress is calculated based on three different degrees of breakouts at each point $( \pm 2$ $\mathrm{m}$ ), which are plotted in Fig. 12 to show the possible range of $S_{H \text { max }}$. These stress-polygon graphics help to constrain and delineate the stress regime in the study area by establishing a smaller polygon region within a less constrained larger polygon. A 10-degree change in observed breakout width would substantially influence the polygon graphic. Given the very small depth interval over which the breakout widths might vary, they present a vast range of possible $\mathrm{S}_{H \max }$ values. 


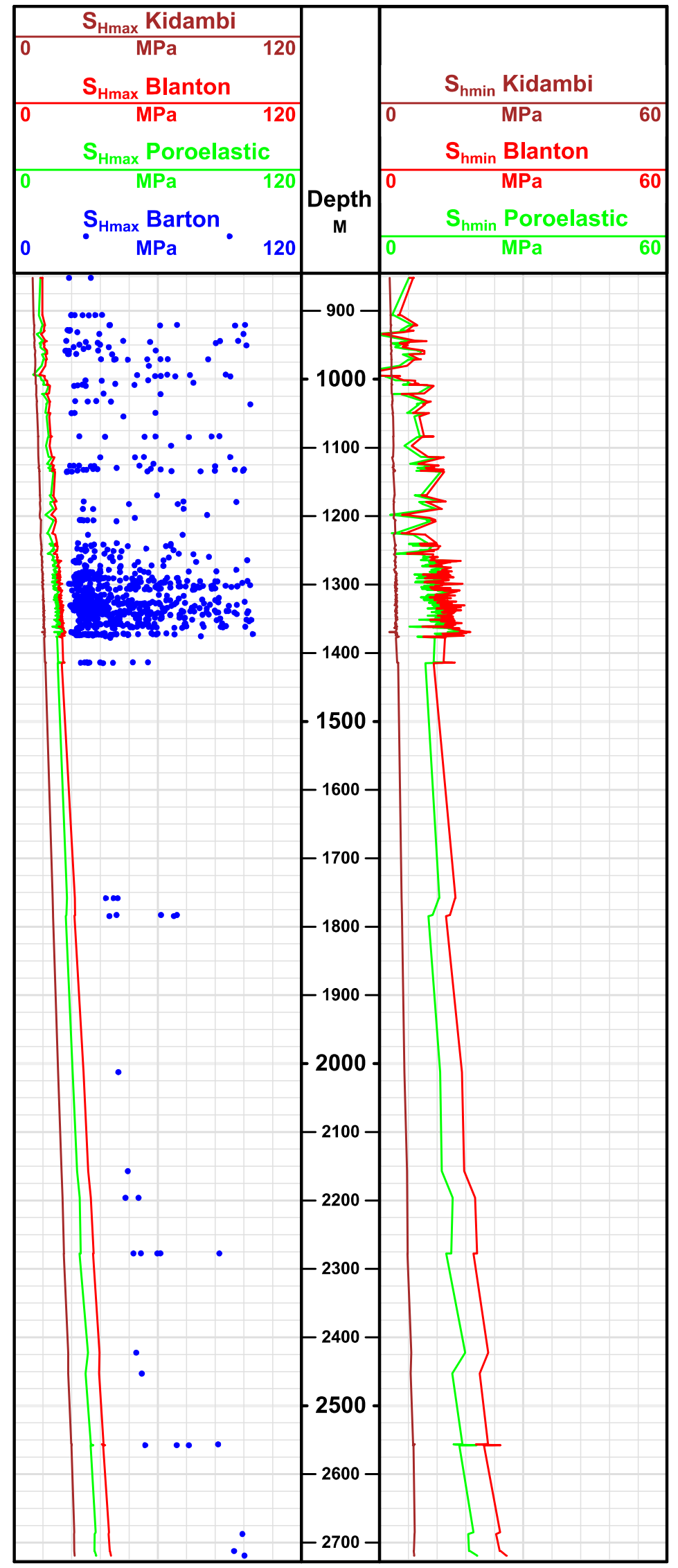

Fig. 9. Estimated values for in-situ horizontal stresses $\left(S_{H \max }\right.$ and $\left.\mathrm{S}_{h \min }\right)$ based on Barton, and other methods. $\mathrm{S}_{H \max }$ values derived from Barton's method distributed over a wide range and showing a considerable difference with other methods. There is though a general increasing trend with depth visible in all curves. The separations of the curves increase as a function of depth for both in-situ stresses. 
Table 3. Characteristics of four selected points for stress polygon analysis.

\begin{tabular}{llllllll}
\hline Point & $\begin{array}{l}\text { Depth } \\
\text { [meters] }\end{array}$ & $\begin{array}{l}\text { Gamma Ray } \\
{[\mathrm{GAPI}]}\end{array}$ & $\begin{array}{l}\text { E static } \\
{[\mathrm{GPa}]}\end{array}$ & $\begin{array}{l}\text { G static } \\
{[\mathrm{GPa}]}\end{array}$ & $\begin{array}{l}\text { K static } \\
{[\mathrm{GPa}]}\end{array}$ & $\begin{array}{l}\text { Poisson's } \\
\text { ratio }\end{array}$ & $\begin{array}{l}\text { UCS } \\
{[\mathrm{MPa}]}\end{array}$ \\
\hline $\mathrm{a}$ & 851 & 98 & 6.1 & 2.4 & 4.3 & 0.267 & 27.3 \\
$\mathrm{~b}$ & 1049 & 174 & 6.2 & 2.4 & 4.4 & 0.267 & 27.8 \\
$\mathrm{c}$ & 1132 & 141 & 4.7 & 1.8 & 3.4 & 0.270 & 21.9 \\
$\mathrm{~d}$ & 1352 & 145 & 8.1 & 3.1 & 5.6 & 0.263 & 35.4 \\
\hline
\end{tabular}
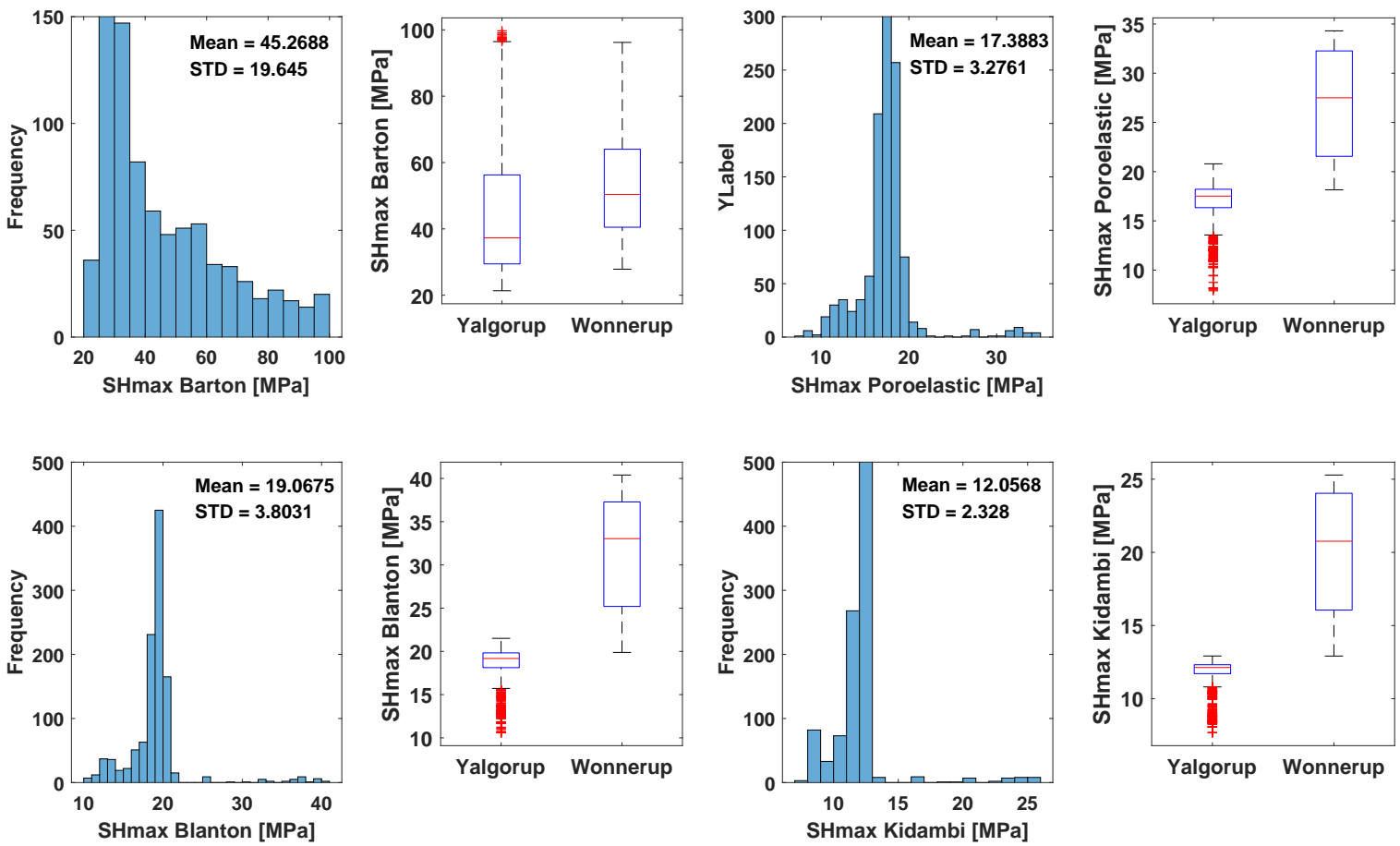

Fig. 10. Histogram and boxplot of $S_{H \max }$ acquired from Barton, and other methods. Barton's method values are distributed in a wide range, reflecting the same distribution of breakout widths. The means and standard deviations of the Blanton, Poroelastic and Kidambi methods are similar with the latter having the lowest standard deviation. Although the higher values of $S_{H \max }$ for Wonnerup member is mostly because of its greater depth, the values from Barton show a wide overlapping range for both Yalgorup and Wonnerup.

Such an uncertainty substantially reduced the reliability of the application of breakouts data in estimating maximum horizontal principal stress to reasonable degrees of accuracy in the studied area. The estimation of $\mathrm{S}_{H \max }$ from breakouts information from image logs relies on the calculated width of the induced fractures. Different estimates of width lead to a substantial range of calculated values for $\mathrm{S}_{H \max }$ at a given depth and a given $S_{h \min }$. The wider the breakouts, the more limited the associated stress polygon, and the more unstable the borehole wall is deemed to be.

For example, in the Fig. 12a, the stress polygon is shown for depth $851 \mathrm{~m}$ where a $50^{\circ}$ wide breakout was observed. However, the uncertainty of the width of the breakout taking into account the two meters above and below that depth point varies from $60^{\circ}$ to $40^{\circ}$. Such large uncertainties can result in a substantial possible range of stress magnitude estimates applying to limited depth intervals. The shaded zones in the polygons shown in Fig. 12 provide the most likely ranges for $S_{H \max }$ based on the most abundant breakouts and the $S_{h \text { min }}$ gradient observed in Harvey-1 at each specific depth evaluated. This implies that any wellbore failure that leads to a $S_{H \max }$ estimate outside the shaded zone in Fig. 12 should be considered as erroneous. This means that as the breakout width increases the range of possible horizontal stress becomes more limited (e.g., Fig. 12c) implying that a wellbore is more prone to fail. In contrast, when breakouts occur with a small width (e.g., Fig. 12a) a broader polygon results implying a greater range of possible horizontal stress.

\section{Conclusion}

In this study a comparison between the maximum horizontal stresses derived from breakout-width and poroelastic methods have been calculated and compared. The results obtained for the breakout method are distinct from the other methods and shows a wide scattered range of $\mathrm{S}_{H \max }$ values. This scattered calculated-stress pattern can be attributed to the wide range and large standard deviation of the breakout widths. $S_{h \text { min }}$ values calculated by all poroelastic methods tare comparable with each other in magnitude. This suggests that the wide range of calculated $\mathrm{S}_{H \max }$ values might not be 


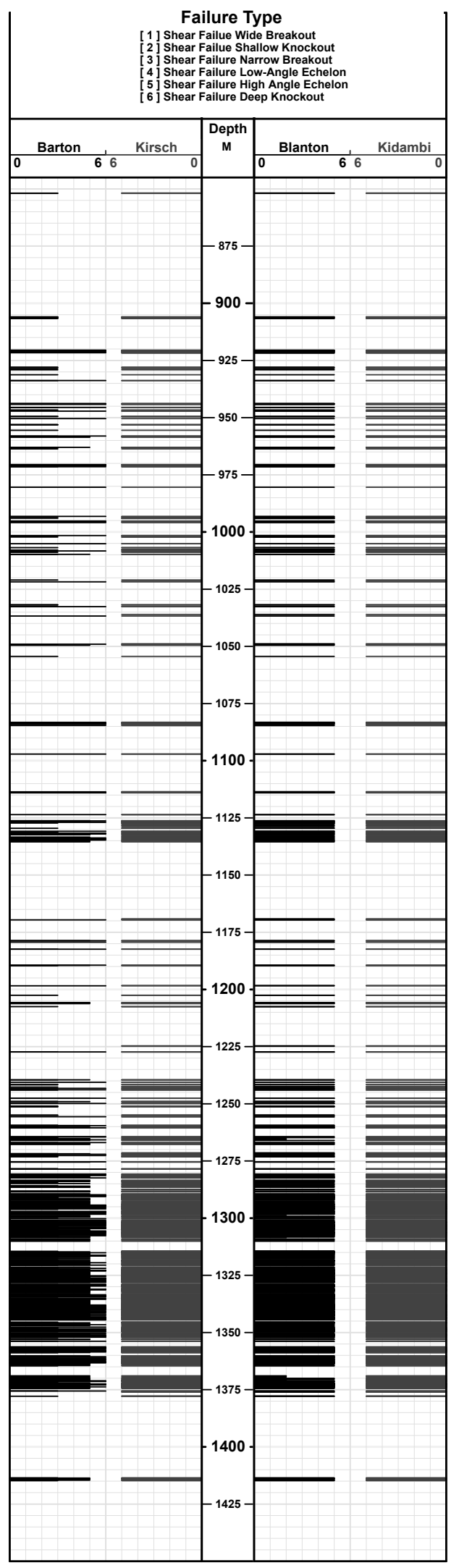

Fig. 11. Identified shear-failures for Harvey-1 based upon estimated $S_{H \max }$ values from all four methods. This model is limited to depths in which breakouts occurred. The failure types with respect to the Blanton, Kidambi and poroelastic $\mathbf{S}_{H \text { max }}$ values are mostly classified under high angle echelon. In contrast, narrow breakout, deep knockout and high angle echelon are frequent fracture types from Barton's point of view. 

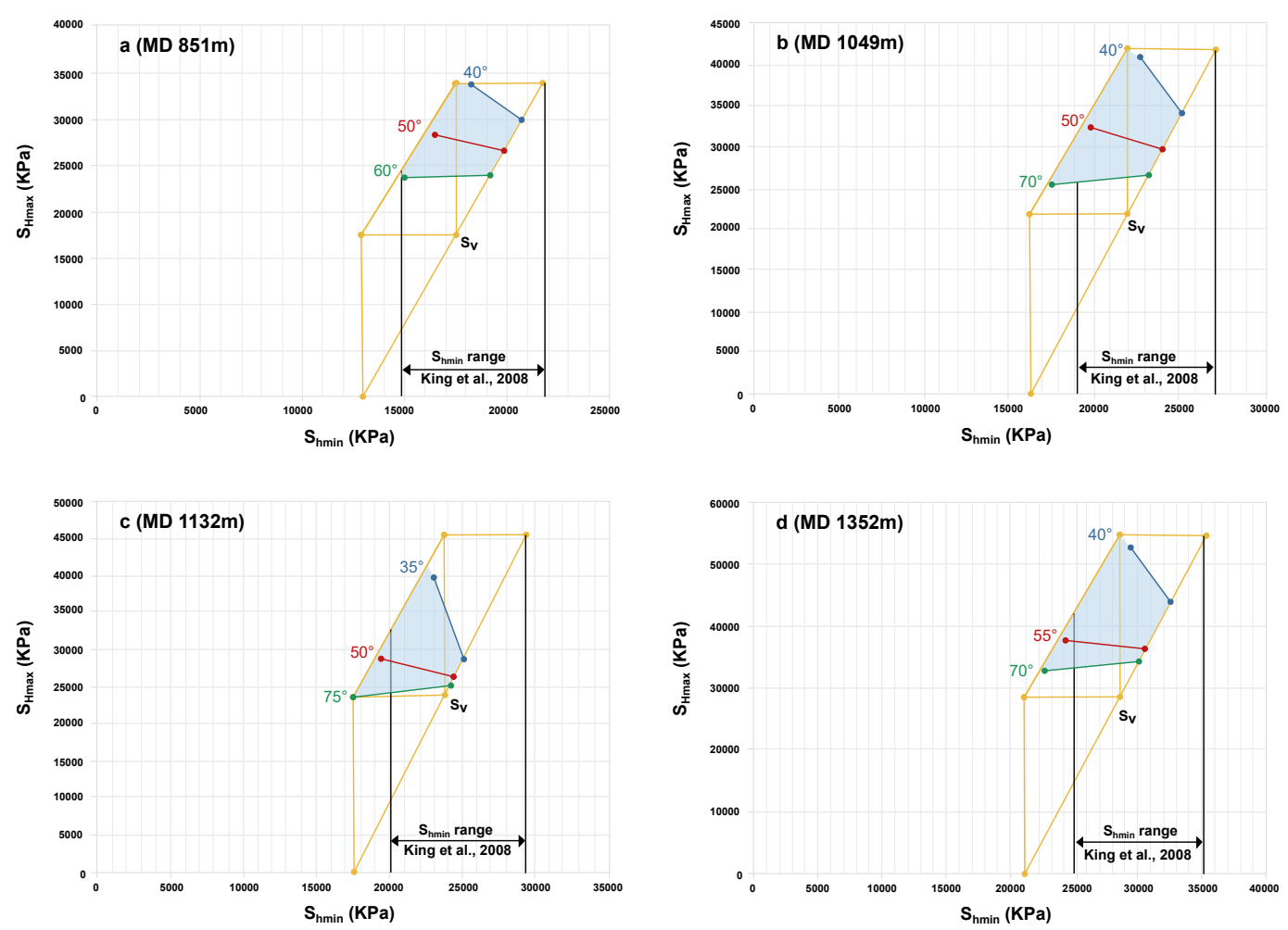

Fig. 12. Stress polygon or zobackogram at four depth points where breakouts were frequent. a, b, c and d are $851,1,049,1,132$ and $1,302 \mathrm{~m}$ respectively. $S_{h \min }$ range of King et al. (2008) for Harvey-1 was used and $S_{H \max }$ for three different widths at each point were calculated and plotted. The red lines are the average width at each depth point and blue and green lines are width at \pm 2 meters of the depth points, respectively.

reasonable. This mismatch in $\mathrm{S}_{H \text { max }}$ calculated by different methods is also associated with discrepancies in the failuretype classification of the wellbore, by the different methods. Breakouts are known to result in a wide range of failure types. The poroelastic equations classify all the fractures as high-angle echelon shear failures. These results reveal that failures within the Harvey-1 borehole do occur with different shapes (some non-planar) and displaying a range of angles to the horizontal plane. On the other hand, a key assumption of Barton et al. (1988)'s equation is that breakouts are considered to be limited to features occurring in the horizontal plane. Furthermore, the analysis of stress polygons reveals that maximum horizontal stresses from breakouts show very irregular patterns at different specific depth intervals in the Harvey-1 well. Many of those estimates fall outside the feasible $\mathrm{S}_{H \max }$ zones delimited by the stress polygons. These findings emphasize the importance to develop more realistic approaches to constrain estimations of rock stresses from wellbore breakout data.

Overall, the occurrence of breakouts within a wellbore might not be necessarily in the horizontal plane perpendicular to the borehole axis. In addition, measuring breakout width from images can be associated with unwanted uncertainties relating to the type of breakouts and/or abrupt changes of their width across small depth intervals. Conducting stress polygon analysis is essential to obtain meaningful breakout stress-constraint limits. This is because stress polygons are in- dependent of the uncertainties associated with breakout width measurements and cover a broad range of possible widths. The failure type identification based upon $\mathrm{S}_{H \text { max }}$ values derived from poroelastic methods can also help calibrate the breakout outcomes. These findings emphasize the importance of integrating stress-field analysis from several methods in order to generate realistic estimates of $\mathrm{S}_{H \max }$ from breakout data.

\section{Acknowledgement}

All the data and information required for this research was downloaded from the Western Australian Petroleum and Geothermal Information Management System (WAPIMS) and we would like to thank the Department of Mines, Industry Regulations and Safety of Western Australia for providing that data platform. The first author would like to thank Ali Mohammad Bagheri and Farhad Khoshbakht from the Research Institute of Petroleum Industry, Iran, who provided useful assistance with the processing of image logs.

\section{Conflict of interest}

The authors declare no competing interest.

Open Access This article is distributed under the terms and conditions of the Creative Commons Attribution (CC BY-NC-ND) license, which permits unrestricted use, distribution, and reproduction in any medium, provided the original work is properly cited. 


\section{References}

Al-Ajmi, A. M., Zimmerman, R. W. Stability analysis of vertical boreholes using the Mogi-Coulomb failure criterion. International Journal of Rock Mechanics and Mining Sciences, 2006, 43(8): 1200-1211.

Ali, A. H. A., Brown, T., Delgado, R., et al. Watching rocks change-mechanical earth modeling. Oilfield Review, 2003, 15(1): 22-39.

Archer, S., Rasouli, V. A log based analysis to estimate mechanical properties and in-situ stresses in a shale gas well in North Perth Basin. Petroleum and Mineral Resources, 2012, 21: 122-135.

Barton, C. A., Zoback, M. D., Burns, K. L. In-situ stress orientation and magnitude at the Fenton Geothermal Site, New Mexico, determined from wellbore breakouts. Geophysical Research Letters, 1988, 15(5): 467-470.

Bastos, A. C., Dillon, L. D., Vasquez, G. F., et al. Corederived acoustic, porosity \& permeability correlations for computation pseudo-logs. Geological Society Special Publications, 1998, 136(1): 141-146.

Blanton, T. L., Olson, J. E. Stress magnitudes from logs: Effects of tectonic strains and temperature. SPE Reservoir Evaluation \& Engineering, 1999, 2(1): 62-68.

Crostella, A., Backhouse, J. Geology And Petroleum Exploration of The Central And Southern Perth Basin. Perth WA, Western Australia, Geological Survey of Western Australia, 2000.

Delle Piane, C., Timms, N. E., Saeedi, A., et al. Faciesbased rock properties distribution along the Harvey 1 stratigraphic well. Working Paper, 2013.

Edimann, K., Somerville, J. M., Smart, B. G. D., et al. Predicting rock mechanical properties from wireline porosities. Paper SPE 47344 Presented at SPE Rock Mechaincs in Petroleum Engineering, Trondheim, Norway, 8-10 July, 1998.

Farag, A., Mughairy, S. A., Al-Hasani, H. Y., et al. Integration of conventional logs, core, borehole images, and 3D seismic, a rule of geological modeling in tight clastics gas deep reservoirs, Oman. Paper SPE 132033 Presented at SPE Deep Gas Conference and Exhibition, Manama, Bahrain, 24-26 January, 2010.

Faraji, M. A., Kadkhodaie, A., Rezaee, R., et al. Integration of core data, well $\operatorname{logs}$ and seismic attributes for identification of the low reservoir quality units with unswept gas in the carbonate rocks of the world's largest gas field. Journal of Earth Science, 2017, 28(5): 857-866.

Farquhar, R. A., Somerville, J. M., Smart, B. G. D., et al. Porosity as a geomechanical indicator: an application of core and log data and rock mechanics. Paper SPE 28853 Presented at European Petroleum Conference, London, United Kingdom, 25-27 October, 1994.

Farrokhrouz, M., Asef, M. R., Asef, M. R., et al. Evaluation of empirical correlations for Biot's coefficient prediction. The 15th International Workshop on Seismic Anisotropy, 2012.

Fjar, E., Holt, R. M., Raaen, A. M., et al. Petroleum Related Rock Mechanics. Amsterdam, Netherlands, Elsevier
Science, 2008.

Folkestad, A., Veselovsky, Z., Roberts, P. Utilising borehole image logs to interpret delta to estuarine system: A case study of the subsurface Lower Jurassic Cook Formation in the Norwegian northern North Sea. Marine Petroleum Geology, 2012, 29(1): 255-275.

Gough, D. I., Bell, J. S. Stress orientations from borehole wall fractures with examples from Colorado, east Texas, and northern Canada. Canadian Journal of Earth Sciences, 1982, 19(7): 1358-1370.

Haimson, B. C., Chang, C. True triaxial strength of the KTB amphibolite under borehole wall conditions and its use to estimate the maximum horizontal in situ stress. Journal of Geophysical Resrarch: Solid Earth, 2002, 107(B10): ETG 15-1-ETG 15-14.

Haimson, B., Cornet, F. ISRM suggested methods for rock stress estimation-part 3: Hydraulic fracturing (HF) and/or hydraulic testing of pre-existing fractures (HTPF). Intternational Journal of Rock Mechanics and Mining Sciences, 2003, 40(7-8): 1011-1020.

Haimson, B., Lee, H. Borehole breakouts and compaction bands in two high-porosity sandstones. Intternational Journal of Rock Mechanics and Mining Sciences, 2004, 41(2): 287-301.

Haimson, H. C., Herrick, C. G. Borehole breakouts-a new tool for estimating in situ stress? Paper ISRM 1986028 Presented at ISRM International Symposlum, Stockholm, Sweden, 31 August-3 September, 1986.

Heidbach, O., Rajabi, M., Cui, X., et al. The World Stress Map database release 2016: Crustal stress pattern across scales. Tectonophysics, 2018, 744: 484-498.

Höcker, C., Eastwood, K. M., Herweijer, J. C., et al. Use of dipmeter data in clastic sedimentological studies. AAPG Bulletin, 1990, 74(2): 105-118.

Hudson, J., Harrison, J., Popescu, M. Engineering rock mechanics: an introduction to the principles. Applied Mechanics Reviews, 2002, 55(2): B30.

Hurley, N. F., Zhang, T. Method to generate full-bore images using borehole images and multipoint statistics. SPE Reservoir Evaluation \& Engineering, 2011, 14(2): 204214.

Jeanne, P., Rutqvist, J., Wainwright, H. M., et al. Effects of in situ stress measurement uncertainties on assessment of predicted seismic activity and risk associated with a hypothetical industrial-scale geologic $\mathrm{CO}_{2}$ sequestration operation. Journal of Rock Mechanics Geotechnical Engineering, 2016, 8(6): 873-885.

Kidambi, T., Kumar, G. S. Mechanical earth modeling for a vertical well drilled in a naturally fractured tight carbonate gas reservoir in the Persian Gulf. Journal Petroleum Science and Engineering, 2016, 141: 38-51.

King, R. C., Hillis, R. R., Reynolds, S. D. In situ stresses and natural fractures in the Northern Perth Basin, Australia. Australian Journal of Earth Sciences, 2008, 55(5): 685701.

Lin, H., Oh, J., Canbulat, I., et al. Experimental and analytical investigations of the effect of hole size on borehole breakout geometries for estimation of in situ stresses. 
Rock Mechanics and Rock Engineering, 2020a, 53(2): 781-798.

Lin, H., Singh, S., Oh, J., et al. A combined approach for estimating horizontal principal stress magnitudes from borehole breakout data via artificial neural network and rock failure criterion. International Journal of Rock Mechanics Mining Sciences, 2020b, 136: 104539.

Luthi, S. Geological Well Logs: Their Use in Reservoir Modeling. Heidelberg, Germany, Springer Science \& Business Media, 2001.

Millar, A., Reeve, J. GSWA Harvey 1 well completion and preliminary interpretation report, southern Perth Basin. Geological Survey of Western Australia Record, 2014.

Mogi, K. Fracture and flow of rocks under high triaxial compression. Journal of Geophysical Research, 1971, 76(5): 1255-1269.

Moos, D., Zoback, M. D. Utilization of observations of well bore failure to constrain the orientation and magnitude of crustal stresses: Application to continental, Deep Sea Drilling Project, and Ocean Drilling Program boreholes. Journal of Geophysical Research: Solid Earth, 1990, 95(B6): 9305-9325.

Nie, X., Zou, C., Pan, L., et al. Fracture analysis and determination of in-situ stress direction from resistivity and acoustic image logs and core data in the Wenchuan Earthquake Fault Scientific Drilling Borehole-2 (50-1370 m). Tectonophysics, 2013, 593: 161-171.

Pašić, B., Gaurina Medimurec, N., Matanović, D. Wellbore instability: Causes and consequences. Rudarsko-geološkonaftni zbornik, 2007, 19(1): 87-98.

Peng, S., Zhang, J. Engineering Geology for Underground Rocks. Heidelberg, Germany, Springer Science \& Business Media, 2007.

Plumb, R. A. Influence of composition and texture on the failure properties of clastic rocks. Paper SPE 28022 Presented at Society of Petroleum Engineers, Delft, Netherlands, 29-31 August, 1994.

Poppelreiter, M., Balzarini, M. A., Sousa, P. D., et al. Structural control on sweet-spot distribution in a carbonate reservoir: Concepts and 3-D models (Cogollo Group, Lower Cretaceous, Venezuela). AAPG Bulletin, 2005, 89(12): 1651-1676.

Ranjbar, A., Hassani, H., Shahriar, K. 3D geomechanical modeling and estimating the compaction and subsidence of Fahlian reservoir formation (X-field in SW of Iran). Arabian Journal of Geosciences, 2017, 10(5): 116.

Rasouli, V., Pervukhina, M., Müller, T. M., et al. In-situ stresses in the Southern Perth Basin at the GSWA Harvey-
1 well site. Exploration Geophysics, 2013, 44(4): 289298.

Sahara, D. P., Schoenball, M., Gerolymatou, E., et al. Analysis of borehole breakout development using continuum damage mechanics. International Journal of Rock Mechanics Mining Sciences, 2017, 97: 134-143.

Takahashi, M., Koide, H. Effect of the intermediate principal stress on strength and deformation behavior of sedimentary rocks at the depth shallower than $2000 \mathrm{~m}$. Paper ISRM 1989003 Presented at ISRM International Symposium, Pau, France, 30 August-2 September, 1989.

Tingay, M., Reinecker, J., Müller, B. Borehole breakout and drilling-induced fracture analysis from image logs. World Stress Map Project, 2008, 1-8.

Tixier, M. P., Loveless, G. W., Anderson, R. A. Estimation of formation strength from the mechanical-properties log (incudes associated paper 6400). Journal Petroleum Technololgy, 1975, 27(3): 283-293.

Vernik, L., Zoback, M. D. Estimation of maximum horizontal principal stress magnitude from stress-induced well bore breakouts in the Cajon Pass scientific research borehole. Journal Geophysics Reserach: Solid Earth, 1992, 97(B4): 5109-5119.

$\mathrm{Xu}, \mathrm{C}$. Interpreting shoreline sands using borehole images: A case study of the Cretaceous Ferron Sandstone Member in Utah. AAPG Bulletin, 2007, 91(9): 1319-1338.

$\mathrm{Xu}, \mathrm{C}$., Richter, P., Russell, D., et al. Porosity partitioning and permeability quantification in vuggy carbonates using wireline logs, Permian Basin, West Texas. Petrophysics, 2006, 47(1): 13-22.

Zhang, H., Yin, S., Aadnoy, B. S. Poroelastic modeling of borehole breakouts for in-situ stress determination by finite element method. Journal Petroleum Science Engineering, 2018, 162: 674-684.

Zheng, Z., Kemeny, J., Cook, N. Analysis of borehole breakouts. Journal Geophysical Research: Solid Earth, 1989, 94(B6): 7171-7182.

Zoback, M. D. Reservoir Geomechanics. Cambridge, United Kingdom, Cambridge University Press, 2010.

Zoback, M. D., Barton, C. A., Brudy, M., et al. Determination of stress orientation and magnitude in deep wells. Intternational Journal of Rock Mechanics Mining Sciences, 2003, 40(7-8): 1049-1076.

Zoback, M. D., Moos, D., Mastin, L., et al. Well bore breakouts and in situ stress. Journal Geophysical Research: Solid Earth, 1985, 90(B7): 5523-5530. 